\title{
The presentation of symptomatic heart disease in infancy based on 10 years' experience (1973-82) Implications for the provision of services
}

\author{
D J SCOTT, M L RIGBY, G A H MILLER, E A SHINEBOURNE
}

From the Department of Paediatric Cardiology, Brompton Hospital, London

SUMMARY The diagnoses and age at presentation of 1665 infants with symptomatic heart disease, who were admitted to the Brompton Hospital, London, during the period 1973-82 were reviewed. The frequency of certain conditions had changed during the period of the study. Complete transposition of the great arteries and critical aortic stenosis had become less common, whereas the frequency of right ventricular outflow tract obstruction, and of critical pulmonary stenosis in particular, had increased. Several conditions, including coarctation of the aorta, hearts with univentricularatrioventricular connexion, and double outlet ventricle, formed a higher proportion of cases in the present series than in the New England Regional Infant Cardiac Program study, whereas the proportion of cases of atrial septal defect, hypoplastic left heart syndrome, and pulmonary atresia with intact septum was smaller. Most of the cyanotic infants presented during the first 14 days of life at the time of ductal closure. As expected this was also true of other duct dependent circulatory disorders such as aortic coarctation and interrupted aortic arch. Acyanotic infants with potentially large left to right shunts tended to present during the second month of life, when the pulmonary vascular resistance fell.

This study emphasises that most symptomatic infants with heart disease present during the first two months of life. As a consequence the provision of expert neonatal and infant medical services is an integral part of any paediatric cardiac service.

The incidence of congenital heart disease in the United Kingdom has been reported to be between 5.5 and 5.9 per 1000 live births. ${ }^{2}$ These figures are slightly lower than those obtained from studies performed in Europe and North America, which give an incidence of between 5.7 and 8.6 per 1000 live births. ${ }^{3-6}$

The most recent British study ${ }^{2}$ of the incidence of congenital heart disease in children born between 1957 and 1971 concluded that over three five year periods the overall incidence had remained constant but that there had been a change in the incidence of five major conditions. Uncomplicated ventricular septal defect and atrioventricular septal defect were increasing in frequency, whereas the incidence of ven-

Requests for reprints to Dr E A Shinebourne, Brompton Hospital, Fulham Road, London SW3 6HP.

Accepted for publication 15 May 1984 tricular septal defect associated with right ventricular outflow tract obstruction (tetralogy of Fallot, pulmonary stenosis, or atresia with ventricular septal defect), the hypoplastic left heart syndrome, and ostium secundum atrial septal defect was decreasing.

While providing a guide to the likely prevalence of certain conditions overall incidence includes a large number of asymptomatic infants. The ongoing population based study of the New England Regional Infant Cardiac Program (NERICP) has estimated the incidence of symptomatic heart disease-that is, infants requiring cardiac catheterisation or cardiac surgery and infants who died of cardiac disease-at 2.6 per 1000 live births. ${ }^{7}$ If this figure is combined with prevalence figures for specific conditions a better guide to incidence and the need for provision of care will be obtained. The New England study has provided diagnostic frequencies of lesions presenting in the first year of life and has suggested higher frequencies of certain lesions, including transposition of the 
great arteries, hypoplastic left heart syndrome, and other complex heart lesions, than those found in total occurrence data. These findings, together with the finding that $76-95 \%$ (mean $85 \%$ ) of symptomatic heart disease presents during the first year of life, 12468 led us to perform our study which examines the frequency distribution and presentation of symptomatic heart abnormalities in children admitted to the Brompton Hospital, London, during the first year of life.

During the past decade both regional neonatal and paediatric cardiac services have improved, ${ }^{9}$ and with better postgraduate education it might be expected that earlier referral to a specialist unit would have occurred. At our hospital, this is particularly so as joint paediatric cardiology clinics are held in local hospitals with general paediatricians. Thus virtually all symptomatic infants born in areas covered by these hospitals are identified and referred for further investigation when necessary. In addition, the incidence of certain conditions might be expected to have altered owing to the survival of infants who previously would have been stillborn, since the pattern and incidence of congenital heart disease in this group are known to differ from those of the population as a whole. 256 Since the most significant improvements in care have been made relatively recently it might be expected that changes would have occurred within the past decade as well.

\section{Patients and methods}

\section{DEFINITIONS AND CLASSIFICATION OF \\ HEART DISEASE}

The accurate definition of a condition is important when comparing incidence rates, a point made by Mitchell and others in their study on the incidence of congenital heart disease. ${ }^{5}$ In our study we used the same definition of congenital heart disease as Mitchell, who defined it as "a gross structural abnormality of the heart or intrathoracic great vessels that is actually or potentially of functional significance." In common with Mitchell, we excluded abnormalities of the systemic veins, such as persistent left superior vena cava or inferior vena cava-azygos continuity. We also excluded anomalies of the systemic artery branches. In contrast, we included persistent ductus arteriosus when it occurred within the first 14 days of life and was the only abnormality in a symptomatic infant. ${ }^{10}$ Persistent ductus arteriosus was also considered to be significant when it occurred in association with persistent fetal or transitional circulation.

We defined symptomatic heart disease as that occurring in infants who were either cyanosed, had hypercyanotic spells, or were in heart failure, and were admitted to our unit. Asymptomatic infants with cardiac murmurs were not included within this definition since they were not usually referred for admission but were seen either locally in the joint cardiac clinics that we run with local paediatricians or in the outpatient department of our hospital.

In the study we used the classification of congenital heart disease as shown in Tables 1 and 2. In Table 1 lesions which are commonly associated are grouped together and classified further according to their symptomatic presentation. Since the placement of complex cardiac abnormalities was difficult we devised a method modified from that used in the NERICP study to identify the dominant lesion in these hearts. In Table 2 using the nomenclature described by Tynan $e a^{11}$ we listed the lesions which we considered to be more complex at the top and those of lesser importance at the bottom. This was done for convenience so that complex hearts with more than one lesion were then classified according to the dominant lesion, as listed in Table 2 . Thus coarctation of the aorta occurring in a heart with a univentricular-atrioventricular connexion was coded as double inlet ventricle not coarctation. For the purpose of classification, if pulmonary atresia occurred in the same heart it was ignored. Similarly, total anomalous pulmonary venous connexion was discounted when associated with cor triatriatum. Lesions such as Ebstein's anomaly, atrial isomerism, and secundum atrial septal defect were considered to be of minor importance unless they occurred in isolation.

In common with most classifications ours is not entirely satisfactory, and while lesions at the top of Table 2 will be fully reported there will be underreporting of conditions at the bottom. This means that the frequency of conditions such as coarctation of the aorta and pulmonary stenosis, which are frequently found in complex congenital heart disease, will be underestimated even though they may be the dominant lesion in these hearts from a functional point of view.

\section{STUDY POPULATION}

Infants aged 0-365 days, whose first admission to the Brompton Hospital was during the period 1973-82, were included in the study, which was carried out retrospectively. If infants had undergone cardiac catheterisation the diagnosis was obtained from these data. Where the diagnosis had been revised in the light of subsequent operation, repeat cardiac catheterisation, echocardiography, or postmortem examination the final diagnosis was used. In infants who had not undergone cardiac catheterisation at the Brompton Hospital the diagnosis was obtained from the case notes. Infants with non-structural heart disease were excluded from the study. In cases of complex heart disease lesions were given priority in accordance with 
Table 1 Classification of congenital heart disease according to common association and presentation of symptoms

\begin{tabular}{|c|c|c|c|}
\hline \multicolumn{4}{|c|}{ Cyanotic } \\
\hline Complete transposition $(T G A)^{\star}$ & $\begin{array}{l}R V \text { ougfow tract obstruction } \\
(R V O T O)\end{array}$ & Common mixing & Right to left shunts \\
\hline \multirow[t]{2}{*}{$\begin{array}{l}\text { TGA } \\
\text { TGA and ventricular SD (VSD) } \\
\text { TGA, VSD, and coarctation } \\
\text { TGA and coarctation } \\
\text { TGA and atrioventricular SD } \\
\text { TGA and LV outflow tract } \\
\text { obstruction (LVOTO) }\end{array}$} & $\begin{array}{l}\text { Pulmonary atresia (PA) } \\
\text { PA and VSD } \\
\text { Tetralogy of Fallot } \\
\text { Critical pulmonary stenosis (PS) } \\
\text { and VSD } \\
\text { Critical pulmonary stenosis } \\
\text { PS and LV outflow tract } \\
\text { obstruction }\end{array}$ & $\begin{array}{l}\text { Total anomalous pulmonary } \\
\text { venous connexion } \\
\text { Anomalous systemic } \\
\text { venous return } \\
\text { Double outlet ventriclef } \\
\text { UVH (including absent AV } \\
\text { connexion)S } \\
\text { Truncus arteriosus (TA) } \\
\text { TA and interrupted aortic arch }\end{array}$ & $\begin{array}{l}\text { Persistent fetal circulation } \\
\text { Pulmonary arterial hypertension } \\
\text { Pulmonary AV fistula }\end{array}$ \\
\hline & & anotic & \\
\hline $\begin{array}{l}\text { Left side obstructive lesions } \\
\text { Critical aortic stenosis (LVOTO) } \\
\text { Coarctation } \\
\text { Coarctation and VSD } \\
\text { Coarctation and RVOTO } \\
\text { Interrupted aortic arch }\end{array}$ & $\begin{array}{l}\text { LV muscle disease } \\
\text { Hypertrophic obstructive } \\
\text { cardiomyopathy } \\
\text { Endocardial fibroelastosis } \\
\text { Myocarditis } \\
\text { Anomalous origin of coronary } \\
\text { artery }\end{array}$ & $\begin{array}{l}\text { Left to right shunts } \\
\text { VSD } \\
\text { VSD and persistent ductus } \\
\text { arteriosus } \\
\text { VSD and atrial SD } \\
\text { Atrioventricular SD } \\
\text { Secundum atrial SD } \\
\text { Persistent ductus arteriosus } \\
\text { Systemic AV fistula } \\
\text { Aortopulmonary window }\end{array}$ & $\begin{array}{l}\text { Other' } \\
\text { Hypoplastic left heart syndrome } \\
\text { Congenitally corrected } \\
\text { transpositiont } \\
\text { Absent pulmonary valve } \\
\text { Atrial isomerism } \\
\text { Uhl's anomaly } \\
\text { Ebstein's anomaly } \\
\text { Cor triatriatum } \\
\text { Aortic arch anomaly } \\
\text { Pulmonary artery anomaly }\end{array}$ \\
\hline
\end{tabular}

^Atrioventricular concordance with ventriculoarterial discordance.

†Atrioventricular discordance with ventriculoarterial discordance.

†Further classified into double outlet right ventricle (DORV), DORV with subaortic ventricular SD and pulmonary atresia, DORV with subaortic ventricular SD and critical pulmonary stenosis, and DORV with subpulmonary ventricular SD, and double outlet left ventricle. CClassified into those with double inlet atrioventricular connexion (DIV) and those with absent atrioventricular connexion (either right or left). Cases of DIV were subdivided into those of unspecified type, LV type, RV type, or indeterminate type.

"Cases of left and right atrioventricular valve anomalies (isolated) were classified separately.

SD, septal defect; LV, left ventricular; RV, right ventricular; AV, atrioventricular; UVH, heart with univentricular-atrioventricular connexion.

the list in Table 2. Only one diagnosis was recorded for each infant.

All infants admitted to the hospital were assumed to be symptomatic, and their age at the time of admission was used for the purpose of analysis even if they had been seen elsewhere previously. This information was obtained from admission records, which in the case of the paediatric intensive care unit had been kept since 1973 and in the case of the paediatric ward since 1977. As records of admissions to the paediatric ward were not kept before 1977 it is likely that a few older infants admitted during the period 1973-77 who did not undergo cardiac catheterisation have been omitted from the study.

\section{STATISTICAL ANALYSIS}

In comparing our series with the findings of the New England series (NERICP) the $\chi^{2}$ tests were used to examine the significance of differences between the two groups.

\section{Results}

The cardiac catheterisation data of 1693 infants together with the case notes of a further 454 infants were reviewed. Infants who had undergone catheter- isation on more than one occasion were entered into the study only once, at the time of their initial catheterisation. During the study period 1665 infants were admitted with symptomatic heart disease, and 1360 infants had their diagnoses confirmed by cardiac catheterisation at the Brompton Hospital. The remaining 305 infants had either undergone cardiac catheterisation elsewhere or had their diagnoses established clinically with or without the help of echocardiography. Twelve infants underwent catheterisation and were found to have non-structural cardiac disease: eight had normal hearts, two systemic hypertension, and two were catheterised in order to perform electrophysiological studies. A total of 1653 symptomatic infants with structural heart disease was included in the study, and this is the total which has been used when the percentage distribution of the various lesions is considered.

\section{PRESENTATION OF SYMPTOMATIC INFANTS}

The number of infants presenting during the five year periods 1973-77 and 1978-82 was similar, although there was a $4 \%$ increase during the second five year period with an apparent but statistically insignificant trend for patients to present later (Figs. 1 and 2). The trend towards later presentation was significant when 
Table 2 Classification of congenital heart disease by the dominant lesion in complex cases

Absent atrioventricular connexion

Double inlet atrioventricular connexion

Atrioventricular discordance with ventriculoarterial discordance (congenitally corrected transposition)

Hypoplastic left heart syndrome

Truncus arteriosus

Atrioventricular discordance with ventriculoarterial concordance (complete transposition)

Interrupted aortic arch

Atrioventricular septal defect

Double outlet ventricle

Coarctation of the aorta

Absent pulmonary valve syndrome

Pulmonary atresia

Tetralogy of Fallot

Pulmonary stenosis (infundibular of valvar)

Cor triatriatum

Total anomalous pulmonary venous connexion

Aortopulmonary window

Hypertrophic obstructive cardiomyopathy

Aortic stenosis (subaortic or valvar)

Persistent ductus arteriosus

Pulmonary artery anomalies (with or without associated lung abnormalities)

Atrioventricular valve abnormalities

Ventricular septal defect

Myocardial abnormalities (including endomyocardial fibroelastosis, myocarditis, myocardial infarction, and anomalous origin of a coronary artery)

Atrial isomerism

Ebstein's anomaly

Peripheral pulmonary stenosis

Systemic arteriovenous fistula

Pulmonary arteriovenous fistula

Secundum atrial septal defect

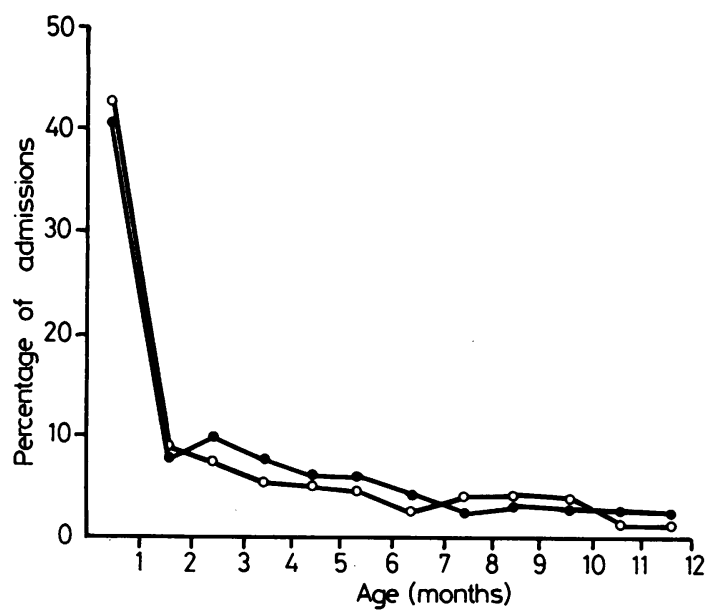

Fig. 1 Frequency distribution of admissions in the first year of life for the periods (O) 1973-77 ( $n=797$ ) and (O) 1978-82 ( $n$ $=868$ ).

our figures were compared with those from the NERICP study ${ }^{7}$ (Table 3).

DISTRIBUTION AND TYPES OF CONGENITAL HEART DISEASE

The distribution of symptomatic congenital heart dis-

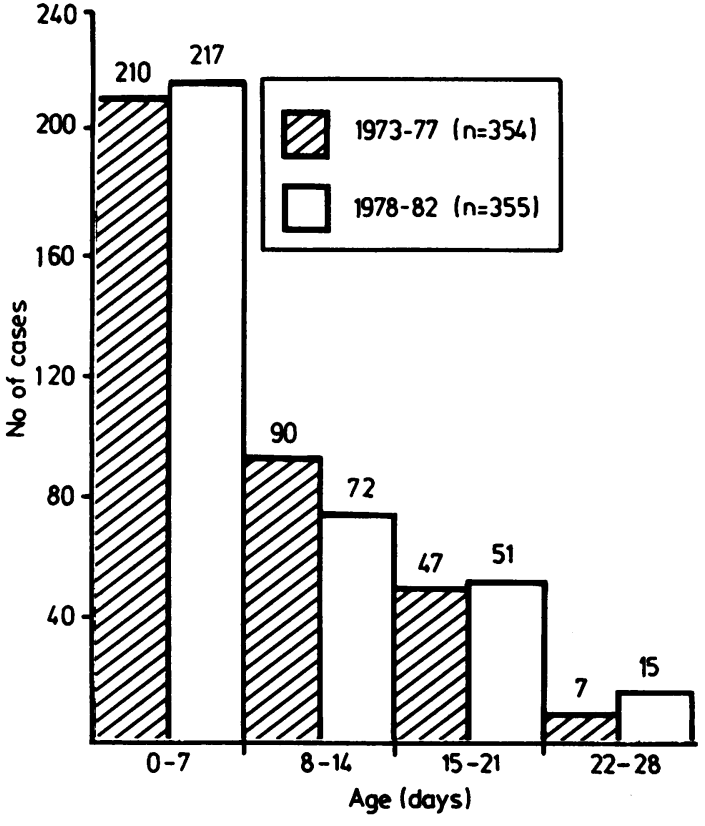

Fig. 2 Frequency distribution of admissions during the first month of life for the periods 1973-77 and 1978-82.

Table 3 Percentage number of admissions within the first week of life compared with the percentage number of admissions within the first two days of life in the New England Regional Infant Cardiac Program (NERICP) series ${ }^{7}$

\begin{tabular}{lll}
\hline Year & $\begin{array}{l}\text { Brompton series } \\
(\text { age 0-7 d) }\end{array}$ & $\begin{array}{l}\text { NERICP series } \\
(\text { age O-2 d) }\end{array}$ \\
\hline 1973 & 28.2 & 29.1 \\
1974 & 26.7 & 30.3 \\
1975 & 28.5 & 30.9 \\
1976 & 24.0 & 29.9 \\
1977 & 24.4 & 34.1 \\
1978 & 21.6 & - \\
1979 & $16.6 \star$ & - \\
1980 & 27.5 & - \\
1981 & 30.4 & - \\
1982 & 26.5 & - \\
\hline
\end{tabular}

*Unit closed for a period of three months to all neonatal admissions.

ease during the first year of life compared with similar data obtained from the NERICP study shows that, in general, there was broad agreement between the two studies with the exception of seven conditions (Table 4). The frequency of coarctation of the aorta, classical tricuspid atresia, other hearts with univentricularatrioventricular connexion, and double outlet right ventricle was significantly increased in our study. The frequency of hypoplastic left heart syndrome, secundum atrial septal defect, and pulmonary atresia with intact septum was significantly lower. 


\section{AGE OF PRESENTATION}

As expected, analysis of the age of presentation showed that certain types of cyanotic heart disease presented early. Complete transposition of the great arteries and severe right ventricular outflow tract obstruction presented within the first 24 hours of life as did hypoplastic left heart syndrome. Severe left ventricular outflow tract obstruction, coarctation of the aorta, and interrupted aortic arch also presented early, although presentation was usually delayed beyond the first day of life. After the first week acyanotic heart disease predominated, with coarctation presenting earlier than ventricular septal defect.

When we compared our findings with those of the NERICP series several important differences emerged (Table 5). In our series, tetralogy of Fallot and uncomplicated ventricular septal defect were significantly less common during the first week of life. In the second week hypoplastic left heart syndrome was less common, whereas in the third week ventricu-

Table 4 Percentage distribution of symptomatic heart disease presenting in the first year of life compared with the NERICP series ${ }^{7}$

\begin{tabular}{|c|c|c|c|c|}
\hline \multirow[t]{2}{*}{ Diagnosis } & \multirow{2}{*}{$\begin{array}{l}\text { Brompton series } \\
(n=1653)\end{array}$} & \multirow{2}{*}{$\begin{array}{l}\text { NERICP series } \\
(n=2381)\end{array}$} & \multicolumn{2}{|c|}{ Statistical analysis } \\
\hline & & & $x^{2}$ & $p$ value \\
\hline $\begin{array}{l}\text { Ventricular septal defect } \\
\text { Complete transpositionf } \\
\text { Tetralogy of Fallot } \\
\text { Coarctation of the aorta } \\
\text { Hypoplastic left heart } \\
\text { Persistent ductus arteriosus } \\
\text { Atrioventricular septal defect } \\
\text { Atrial isomerism } \\
\text { Pulmonary stenosis } \\
\text { Pulmonary atresia (with intact septum) } \\
\text { Secundum atrial septal defect } \\
\text { Total anomalous pulmonary venous connexion } \\
\text { Myocardial disease } \\
\text { Tricuspid atresia } \\
\text { Double inlet ventricle } \\
\text { Aortic stenosis } \\
\text { Double outlet right ventricle } \\
\text { Truncus arteriosus } \\
\text { Corrected transposition } \\
\text { Others }\end{array}$ & $\begin{array}{r}15.4 \\
10.9 \\
9.9 \\
10.5 \\
3.7 \\
6.7 \\
3.9 \\
3.0 \\
1.9 \\
0.5 \\
3.6 \\
2.7 \\
4.7 \\
4.3 \\
1.1 \\
3.0 \\
2.1 \\
0.8 \\
11.3\end{array}$ & $\begin{array}{r}15.7 \\
9.9 \\
8.9 \\
7.5 \\
7.4 \\
6.1 \\
5.0 \\
4.0 \\
3.3 \\
3.1 \\
2.9 \\
2.6 \\
2.6 \\
2.6 \\
2.4 \\
1.9 \\
1.5 \\
1.4 \\
0.9 \\
10.4\end{array}$ & $\begin{array}{r}0.00 \\
0.90 \\
1.20 \\
10.69 \\
25.61 \\
0.36 \\
2.60 \\
0.18 \\
5.71 \\
27.93 \\
2.53 \\
0.01 \\
13.00 \\
10.56 \\
3.57 \\
9.97 \\
2.72 \\
0.20 \\
-\end{array}$ & $\begin{array}{l}\text { NS } \\
N S \\
N S \\
p<0.01 \\
p<0.001 \\
N S \\
N S \\
N S \\
N S \\
p<0.025 \\
p<0.001 \\
N S \\
N S \\
p<0.001 \\
p<0.01 \\
N S \\
p<0.01 \\
N S \\
N S \\
-\end{array}$ \\
\hline
\end{tabular}

^Includes pulmonary atresia with ventricular septal defect.

tAtrioventricular concordance with ventriculoarterial discordance.

$\ddagger$ Atrioventricular discordance with ventriculoarterial discordance.

NS, not significant $(p>0.025)$.

Table 5 Percentage distribution of symptomatic heart disease presenting in the first year of life in the Brompton Hospital (BH) series compared with that in the NERICP series?

\begin{tabular}{|c|c|c|c|c|c|c|c|c|}
\hline \multirow[t]{3}{*}{ Diagnosis } & \multicolumn{8}{|l|}{ Age } \\
\hline & \multicolumn{2}{|l|}{ 0-7 Days } & \multicolumn{2}{|c|}{ 8-14 Days } & \multicolumn{2}{|c|}{ 15-21 Days } & \multicolumn{2}{|c|}{ 6-12 Months } \\
\hline & $\begin{array}{l}B H \\
(n=425)\end{array}$ & $\begin{array}{l}\text { NERICP } \\
(n=896)\end{array}$ & $\begin{array}{l}B H \\
(n=161)\end{array}$ & $\begin{array}{l}\text { NERICP } \\
(n=210)\end{array}$ & $\begin{array}{l}B H \\
(n=96)\end{array}$ & $\begin{array}{l}\text { NERICP } \\
(n=116)\end{array}$ & $\begin{array}{l}B H \\
(n=337)\end{array}$ & $\begin{array}{l}\text { NERICP } \\
(n=230)\end{array}$ \\
\hline $\begin{array}{l}\text { Complete transpositiont } \\
\text { Hypoplastic left heart syndrome } \\
\text { Persistent fetal circulation } \\
\text { Tetralogy of Fallot, PS and VSD } \\
\text { Coarctation } \\
\text { Ventricular septal defect } \\
\text { Pulmonary atresia (intact septum) } \\
\text { Truncus arteriosus } \\
\text { Double inlet ventricle } \\
\text { Atrioventricular septal defect } \\
\text { Persistent ductus arteriosus } \\
\text { Pulmonary stenosis } \\
\text { Myocardial disease } \\
\text { Total anomalous pulmonary } \\
\text { venous connexion } \\
\text { Atrial isomerism } \\
\text { Secundum atrial septal defect }\end{array}$ & $\begin{array}{r}18.8 \\
11.8 \\
8.0 \\
5.2 \\
9.2 \\
3.3 \\
4.7\end{array}$ & $\begin{array}{l}17 \cdot 0 \\
12 \cdot 0 \\
10 \cdot 0 \\
9 \cdot 0^{\star \star} \\
7 \cdot 0 \\
7 \cdot 0^{\star \star \star} \\
7 \cdot 0\end{array}$ & $\begin{array}{r}10 \cdot 6 \\
3 \cdot 7 \\
\\
6 \cdot 2 \\
24 \cdot 2 \\
8 \cdot 1 \\
\\
4 \cdot 3 \\
3 \cdot 1\end{array}$ & $\begin{array}{c}9.0 \\
11.0^{\star \star} \\
6.0 \\
19.0 \\
15.0 \\
4.0 \\
4.0\end{array}$ & $\begin{array}{r}8.3 \\
15.6 \\
9.4\end{array}$ & $\begin{array}{c}8 \cdot 0 \\
16 \cdot 0 \\
20 \cdot 0^{\star}\end{array}$ & $\begin{array}{r}4.7 \\
13.6 \\
5.6 \\
4.5\end{array}$ & $\begin{array}{r}7 \cdot 0 \\
14 \cdot 0 \\
6 \cdot 0 \\
7 \cdot 0\end{array}$ \\
\hline
\end{tabular}

${ }^{\star} \mathrm{p} .0 .05,{ }^{\star \star} \mathrm{p}<0.025,{ }^{\star \star \star} \mathrm{p}<0.01,{ }^{\star \star \star \star \star} \mathrm{p}<0.001$.

+ Atrioventricular concordance with ventriculoarterial discordance.

PS, pulmonary stenosis; VSD, ventricular septal defect. 
lar septal defect was again seen less frequently. Although ventricular septal defect appeared less frequently in the second week of life, the difference did not reach statistical significance. In our series atrial septal defect was much less frequent. This was thought to reflect the reduced prevalence of this condition. We found the high prevalence of ventricular septal defects in the first few weeks of life in the New England series somewhat surprising since this condition usually presents when the pulmonary vascular resistance falls. This can, however, perhaps be explained by paediatric practice in the United States, where most children with cardiac murmurs are referred to a regional cardiac centre for full investigation. ${ }^{7}$ To some extent this was the practice in the United Kingdom in the early part of our study, and as a result we investigated a number of infants with small ventricular septal defects whom we would now not investigate. Currently, we examine only those asymptomatic infants who have evidence of persistently increased pulmonary vascular resistance. Asyrnptomatic infants or those with mild heart failure with ventricular septal defects are usually looked after by general paediatricians, either in consultation with us in one of our locally held joint cardiac clinics or in the outpatient department of our hospital.

Patients referred from cardiac centres abroad, together with those from a few cardiac centres in this country, are usually referred for cardiac surgery. This explains the late presentation of cases such as complete transposition and other more complex cardiac lesions. These patients had usually had palliative pro- cedures performed and were referred to us for corrective surgery.

The frequency of presentation of the main types of congenital heart disease at different ages shows that duct dependent circulatory disorders present in the first month of life, usually in the first week (Table 6). Disorders with a high pulmonary blood flow present from the second month onwards, when the pulmonary vascular resistance has fallen. The peak time for presentation of ventricular septal defect, however, was later than this owing to the fact that, although most of these infants developed symptoms during the second month of life, they were usually first treated at their local hospital and admitted to our unit only when medical management had failed. Thus some children with ventricular septal defect were not considered to have presented to us until 3-4 months of age.

\section{"PREVALENCE" OF CARDIAC LESIONS}

The term "prevalence" is not strictly accurate when applied to the population of infants studied and has for the most part been avoided. Table 7 details the changes in occurrence of cardiac lesions during the two five year periods of the study (1973-77 and 1978-82). The statistically significant differences concern the proportion of cases of complete transposition, which showed a pronounced fall, and right ventricular outflow tract obstruction, which increased in frequency. The frequency of critical aortic stenosis also fell, but this fall may not represent a real change but may reflect the fact that during the early part of the study, when most infants underwent cardiac

Table 6 Relative frequency (\%) of the main types of congenital heart disease at different ages

\begin{tabular}{|c|c|c|c|c|}
\hline \multirow[t]{2}{*}{ Lesion } & \multicolumn{4}{|c|}{ Age (months) } \\
\hline & $\begin{array}{l}0-1 \\
(n=704)\end{array}$ & $\begin{array}{l}0-6 \\
(n=1316)\end{array}$ & $\begin{array}{l}6-12 \\
(n=337)\end{array}$ & $\begin{array}{l}0-12 \\
(n=1653)\end{array}$ \\
\hline $\begin{array}{l}\text { Ventricular septal defect (VSD) } \\
\text { Complete transposition` } \\
\text { Coarctation } \\
\text { Fallot, pulmonary stenosis, VSD } \\
\text { Persistent ductus arteriosus } \\
\text { Tricuspid atresia } \\
\text { Double inlet ventricle } \\
\text { Atrioventricular septal defect } \\
\text { Hypoplastic left heart syndrome } \\
\text { Total anomalous pulmonary venous connexion } \\
\text { Pulmonary stenosis } \\
\text { Double outlet right ventricle } \\
\text { Myocardial disease } \\
\text { Truncus arteriosus } \\
\text { Pulmonary atresia } \\
\text { Critical aortic stenosis } \\
\text { Congenitally corrected transpositiont } \\
\text { Secundum atrial septal defect } \\
\text { Other }\end{array}$ & $\begin{array}{r}5 \cdot 7 \\
15 \cdot 8 \\
13 \cdot 4 \\
5 \cdot 7 \\
2 \cdot 7 \\
5 \cdot 3 \\
5 \cdot 1 \\
2 \cdot 0 \\
8 \cdot 7 \\
3 \cdot 8 \\
1 \cdot 7 \\
2 \cdot 7 \\
2 \cdot 3 \\
2 \cdot 7 \\
4 \cdot 1 \\
1 \cdot 3 \\
0.7 \\
0 \cdot 1 \\
16 \cdot 3\end{array}$ & $\begin{array}{r}13.5 \\
11.5 \\
11.8 \\
7.9 \\
4.9 \\
5.4 \\
4.9 \\
3 \cdot 6 \\
4.6 \\
4 \cdot 3 \\
2.2 \\
2.8 \\
2.3 \\
2.6 \\
2.4 \\
1.3 \\
0.9 \\
0.5 \\
12.8\end{array}$ & $\begin{array}{r}22.8 \\
8.6 \\
5.6 \\
17.5 \\
13.6 \\
2.1 \\
2.1 \\
4.7 \\
- \\
0.9 \\
6.2 \\
3.6 \\
4.5 \\
0.3 \\
-0.3 \\
0.6 \\
0.9 \\
6.3\end{array}$ & $\begin{array}{r}15.4 \\
10.9 \\
10.5 \\
9.9 \\
6.7 \\
4.7 \\
4.3 \\
3.9 \\
3.7 \\
3.6 \\
3.0 \\
3.0 \\
2.7 \\
2.1 \\
1.9 \\
1.1 \\
0.8 \\
0.5 \\
11.3\end{array}$ \\
\hline
\end{tabular}

*Atrioventricular concordance with ventriculoarterial discordance.

†Atrioventricular discordance with ventriculoarterial discordance. 
Table 7 Lesions showing a statistically significant change in occurrence during the 10 year period of the study. Figures are numbers (\%) of patients

\begin{tabular}{lccl}
\hline Lesion & $1973-77$ & $1978-82$ & $\begin{array}{l}\text { Statistical } \\
\text { difference }\end{array}$ \\
\hline $\begin{array}{l}\text { Complete transposition } \\
\begin{array}{l}\text { Right ventricular outflow tract } \\
\text { obstruction }\end{array}\end{array}$ & $113(14.2)$ & $68(7.8)$ & $\mathrm{p}<0.001$ \\
$\begin{array}{l}\text { Critical aortic stenosis } \\
14(15.8)\end{array}$ & $178(20.5)$ & $\mathrm{p}<0.025$ \\
\hline
\end{tabular}

^Atrioventricular concordance with ventriculoarterial discordance.

catheterisation, a few infants whom we would now classify as having the hypoplastic left heart syndrome may have been diagnosed as having critical aortic stenosis.

\section{FACTORS DETERMINING THE TIME OF PRESENTATION}

When the presentation of the various groups of conditions was looked at in detail several interesting points emerged. Most cases of complete transposition of the great arteries without a ventricular septal defect presenting in the first month of life (30/59) did so on day 1 , whereas if there was a ventricular septal defect the presentation was delayed. The occurrence of complete transposition with either atrioventricular septal defect or coarctation of the aorta alone was a rare association, and only one case of each was seen in the 10 year period.

Tetralogy of Fallot tended to present at any time during the first year of life, depending on the severity or at times relative lack of infundibular stenosis. The fact that $25 \%$ (31/125) of patients presented in the first month, with most of these (19/31) in the first week, suggests that this proportion of patients will have severe symptoms and a predominantly duct dependent pulmonary circulation. After the first month the age of presentation mirrored that of uncomplicated ventricular septal defect, and in these patients the degree of right ventricular outflow tract obstruction was not severe. Pulmonary valve stenosis with a ventricular septal defect, and double outlet right ventricle with a subaortic ventricular septal defect and pulmonary stenosis, behaved similarly. As would be expected, pulmonary atresia presented earlier than pulmonary stenosis. There were six cases of combined right and left ventricular outflow tract obstruction, and in these the former was more severe.

Conditions with "common mixing" presented either at birth because of the cyanosis or later when the pulmonary vascular resistance fell and the size of the left to right shunt increased. In many cases, however, there were additional lesions, such as coarctation, which determined the time of presentation.

Cases with left ventricular outflow obstruction, coarctation, and aortic interruption presented in the first month of life (124/217 cases). A later presentation was associated with a milder degree of obstruction. If the obstruction was severe systemic flow was frequently dependent on a persistent ductus ateriosus, and hence closure of the ductus arteriosus was usually the factor which led to the development of symptoms. The association of a ventricular septal defect with coarctation did not appear to influence the time of presentation.

\section{ASSOCIATED LESIONS}

As has been mentioned, the nature of our classification led to the under-reporting of certain lesions. Hearts with univentricular-atrioventricular connexions were often associated with lesions such as pulmonary stenosis, pulmonary atresia, or coarctation; these have not been included. Truncus arteriosus was also associated with hypoplastic left heart on one occasion, whereas hypoplastic left heart was associated with congenitally corrected transposition once. Interrupted aortic arch was associated with complete transposition and ventricular septal defect in one heart. Critical aortic stenosis was seen in three infants with complex lesions.

\section{INCIDENCE OF THE DIFFERENT LESIONS}

Using the figures given for the population served, we may obtain a rough estimate of the actual incidence of selected cardiac lesions based on the assumption that for these conditions all cases will be detected. This enables us to compare our data prevalence with that of other series 1256 which have examined the incidence of specific types of congenital heart disease. Thus if our derived figures of incidence are compared with those from four recent studies there is good agreement for those conditions which present during the first year of life (Table 8). The numbers of cases of hearts with univentricular-atrioventricular connexion are higher than in the other series and may again reflect a real rise in incidence. As expected, the calculated incidence of lesions such as ventricular septal defect and atrial septal defect is lower than in the quoted series since these conditions are frequently asymptomatic and not confined to the first year of life.

\section{Discussion}

The Brompton Hospital acts as a referral centre for cardiac cases both from district general hospitals and from other cardiac centres. Included in the latter category are patients from abroad, who are referred for surgery (mean $8.5 \%$ ). When these cases are excluded the number of admissions to the unit over the past decade has been relatively constant. If it is assumed that the incidence of symptomatic heart disease is 2.6 per 1000 live births ${ }^{7}$ and that the birth rate in 1979, for a population of 49 million in England 
Table 8 Incidence of congenital heart disease which presents within the first year of life compared with the incidence of certain lesions in four other recent studies

\begin{tabular}{|c|c|c|c|c|c|}
\hline \multirow[t]{2}{*}{ Lesion } & \multicolumn{5}{|c|}{ Incidence per 10000 live births } \\
\hline & $\begin{array}{l}\text { Brompton* } \\
(1973-82)\end{array}$ & $\begin{array}{l}\text { Liverpoolt } \\
(1960-69)\end{array}$ & $\begin{array}{l}\text { California } \\
(1959-66)\end{array}$ & $\begin{array}{l}\text { Blackpool }{ }^{2} \\
(1957-71)\end{array}$ & $\begin{array}{l}\text { Multicentres } U S A \\
(1959-67)\end{array}$ \\
\hline $\begin{array}{l}\text { Complete transposition } \\
\text { Pulmonary atresia } \\
\text { Tricuspid atresia } \\
\text { Total anomalous pulmonary venous }\end{array}$ & $\begin{array}{l}2.9 \\
0.5 \\
1.3\end{array}$ & $\begin{array}{l}2.7 \\
0.4 \\
0.9\end{array}$ & $\begin{array}{l}3.2 \\
0.5 \\
0.5\end{array}$ & $\begin{array}{l}3.5 \\
1.0 \\
-\end{array}$ & $\begin{array}{l}2.0 \\
0.9 \\
0.9\end{array}$ \\
\hline $\begin{array}{l}\text { connexion } \\
\text { Double inlet ventricle } \\
\text { Truncus arteriosus } \\
\text { Hypoplastic left heart syndrome }\end{array}$ & $\begin{array}{l}1.0 \\
1.3 \\
0.6 \\
0.9\end{array}$ & $\begin{array}{l}0.7 \\
0.9 \\
0.6 \\
1.6\end{array}$ & $\begin{array}{l}0.5 \\
0.5 \\
2.1 \\
0.5\end{array}$ & $\begin{array}{l}1 \cdot 0 \\
1.0 \\
0.5 \\
2 \cdot 0\end{array}$ & $\begin{array}{l}\overline{0.5} \\
1.3 \\
2.4\end{array}$ \\
\hline
\end{tabular}

$\star^{\star}$ Calculated incidence assuming a referral population of 5.16 million and a birth rate of 12 per 1000, producing 61920 live births per year. †Modified from Dickinson et al. ${ }^{1}$

and Wales, was 12.0 per $1000^{12}$ it can be calculated that the Brompton Hospital provides emergency paediatric cardiological care for a population of $5 \cdot 16$ million $(11 \%$ of the total population of England and Wales). This assumes that all infants with symptomatic heart disease in the population are detected. In view of this our results are reasonably representative of the country as a whole.

As our population size is an estimate, the use of the term prevalence-defined as the proportion of cases in a defined population at a particular point in time-is not strictly correct. When we examined the distribution of cases in our series over the two five year periods and compared them with that in the NERICP study we were observing a change in the proportion of symptomatic infants with particular cardiac conditions. It is possible, although extremely unlikely, that instead of certain lesions having become less common everything else had become more common. Nevertheless, on the basis that the population which we serve has not essentially changed during the 10 year period the proportion of particular cardiac anomalies in our series can reasonably be compared with the prevalence of anomalies in the New England (NERICP) study.

\section{PRESENTATION OF SYMPTOMATIC INFANTS}

If the two cohorts 1973-77 and 1978-82 are compared, both in terms of the numbers of infants presenting and the diagnoses within the two groups, this will give a reasonable guide to trends within the past decade. In terms of overall numbers there is considerable similarity between the two groups, with minor differences being explained in part by the larger number of patients referred from other cardiac centres (mainly abroad) in the second cohort. In 1973 fewer patients were referred, whereas in 1979 the reduced number of admissions can be attributed to the fact that part of the unit was closed for a period of three months; this was due to an outbreak of infection within the unit, which was caused by a particularly "sticky" though non-virulent Escherichia coli. During this period we were unable to accept neonatal admissions.

In the early years (1973-75) the proportion of neonatal admissions was slightly higher than in subsequent years, with the exception of 1980 . This finding correlates well with the number of admissions for non-cardiac disease (respiratory distress syndrome, meconium aspiration, pneumothorax, and other neonatal pulmonary problems causing cyanosis), which was also increased in this period compared with subsequent years. The probable reason for this is that in the absence of specialist neonatal knowledge and "special care" facilities there was a tendency to overdiagnose cyanotic congenital heart disease in the neonatal period, and consequently any cyanosed infant was referred early. This explanation is borne out by the fact that the number of admissions during the first week of life, when most cases of cyanotic heart disease present, was lower in the second cohort.

The NERICP data show that over the period 1973-77 the tendency towards earlier case presentation has increased. This was attributed to an intensive education programme. Over the period of our study considerable efforts were made to establish good communication between ourselves and the general paediatricians, who referred patients. In many cases this resulted in the setting up of cardiac clinics run jointly with paediatricians and held in district general hospitals, so that symptomatic infants were seen locally and appropriate advice given, thus sometimes obviating the need for admission to our unit. Furthermore, if appropriate every encouragement was given to general paediatricians to manage their own infants with symptomatic heart disease; at the same time they were assured of ready access to us for advice and the back up needed in the form of specialist investigations. This provision of local cardiac care is of 
benefit to some families, who would otherwise have to travel long distances.

In the 10 year period of the study the mean number of admissions in the first week of life was $26.4 \%$ during the first five year period and $26.6 \%$ during the second, if the figures for 1979 are excluded. In the New England series $30.9 \%$ of admissions presented during the first $\mathbf{4 8}$ hours of life (Table 3). This figure is significantly higher and reflects the increased centralised care aimed at in the United States and thought desirable in this country. ${ }^{9}$

In the early part of the study we used to admit critically ill infants. Over the second five years this became an infrequent occurrence, and most infants presently admitted to our unit are in reasonable condition. Acid base balance has usually been corrected and infants have often received or are receiving prostaglandin $\mathrm{E}$ infusions and inotropic and at times ventilatory support. We attribute this change to improved local care and the close liaison that we have maintained with our referring paediatricians.

\section{DISTRIBUTION AND TYPES OF CONGENITAL HEART DISEASE}

The distribution of congenital heart disease in our 10 year cohort of infants was compared with similar data from the NERICP study taken over the five years from 1969-74 (Table 4). Direct comparison was difficult for two reasons. Firstly, in the NERICP study the definition of what constituted symptomatic heart disease was unclear, as it was taken as being synonymous with heart disease in infants who had undergone cardiac catheterisation or cardiac surgery or who died of cardiac disease. In our series we included only infants with definite symptoms, and we consider it a reasonable assumption that Fyler $e^{2} a^{7}$ included some infants which by our criteria were asymptomatic. Secondly, there were differences in coding and definition between the two series. Atrial isomerism (heterotaxia) alone is not important functionally and has not been included separately in our classification unless it was the only abnormality. The prevalence of this condition was low and may reflect the fact that some cases were missed in the early part of the study. The failure to include laevoisomerism and dextroisomerism as separate groups may therefore explain the slightly higher frequency of hearts with univentricular-atrioventricular connexion in our series, in which atrial isomerism is relatively frequent. Similarly, we did not code secundum atrial septal defect as a lesion of major importance because patent foramen ovale is a frequent finding in infancy and is often of no functional importance.

Thus secundum atrial septal defects were coded as the diagnosis when they were the sole abnormality leading to symptoms. Ostium primum atrial septal defects were coded with endocardial cushion defects under the generic term atrioventricular septal defect. The diagnosis of complex congenital heart disease has been refined during the past few years, and it is possible, for example, that some hearts with double outlet ventricle and some with univentricularatrioventricular connexion may have been misdiagnosed in the early part of the study. This is borne out by the considerable increase in the number of infants with double outlet ventricle in the second five year cohort. "Univentricular heart" is now coded according to whether it is of left, right, or indeterminate ventricular morphology, whereas during the period of the first cohort the ventricular morphology was often unspecified.

The occurrence of hypoplastic left heart syndrome is significantly lower than in other reported series. This condition presents early, and the relatively small number of cases in our study may be due to several factors. Firstly, in the early part of the study some cases were seen at this hospital as outpatients, had their diagnosis confirmed echocardiographically, and were then returned to the referring hospital without being admitted to our unit. Secondly, the diagnosis may have been made locally, and the infants not referred. Thirdly, the diagnosis may have been missed, so that the infants died locally without referral. We consider that the last explanation is responsible for only a very few cases, since the number of cases of coarctation of the aorta is actually increased when compared with the NERICP data. As the symptoms overlap with hypoplastic left heart syndrome it is unlikely that cases of coarctation are detected and referred, whereas those of hypoplastic left heart are not. Thus we believe that the relative numbers of cases of hypoplastic left heart syndrome presenting to this hospital are lower than those seen in the New England series. There is, however, an alternative explanation. Infants with coarctation and a small left ventricle may be classified in the New England series as having the hypoplastic left heart syndrome. This hypothesis may have some credence because at the Brompton Hospital (14.2\%) and in the New England series (14.9\%) the total percentage of patients with coarctation or the hypoplastic left heart syndrome is similar. Against this is the fact that among the deaths in our series no cases of coarctation of the aorta or the hypoplastic left heart syndrome were reclassified on the basis of necropsy findings.

The increased detection of coarctation of the aorta, which we attribute to our postgraduate education programme, was the most important development noted during the past decade. When undetected, and when causing symptoms in infancy, the condition has a high mortality. It is particularly unfortunate that some cases are missed, when they can usually be 
cured by surgery with a relatively low operative mortality. ${ }^{13}$

We are unable to explain the change in prevalence of complete transposition of the great arteries and right ventricular outflow tract obstruction and therefore suspect a real change in incidence of these conditions.

\section{AGE OF PRESENTATION}

The total prevalence figures for all conditions show that the peak time of presentation is during the first two weeks of life. This is when ductal closure occurs and when duct dependent conditions present. Conditions dependent on a low pulmonary vascular resistance present later, about the second to third month.

A comparison with the North American data (Table 5) shows several important differences. Both tetralogy of Fallot and ventricular septal defect were less common in the first week of life, and we suspect that this is due to our practice of not investigating asymptomatic infants with cardiac murmurs. In the second and third weeks of life ventricular septal defects were again less common, although in the second week the difference did not reach statistical significance. The relative frequency of the hypoplastic left heart syndrome was lower in our study (Table 5), and this difference was largely due to fewer cases presenting in the second week. As this condition has nearly $100 \%$ mortality 135 all cases should be detected-either after admission to hospital or at necropsy of infants dying at home-in the second week of life. In practice, the numbers missed are small, and it seems likely that there is a real difference in incidence and that the later presentation in the NERICP series is due to a delay in diagnosis. As secundum atrial septal defects are rarely symptomatic in infancy ${ }^{14}$ the low number detected in our series is not surprising. The much higher prevalence in the NERICP study again supports our view that many of the differences between the two studies are due to a different interpretation of what constitutes symptoms.

\section{CONCLUSION}

The incidence of complete transposition of the great arteries is likely to be declining, and that of right ventricular outflow tract obstruction is increasing. The numbers of complex cardiac lesions also seem to be on the increase, although this may in part reflect greater recognition and characterisation with cardiac catheterisation, angiography, and cross sectional echocardiography. We have shown that symptomatic infants present at times when there are fundamental changes occurring in the circulation. Our policy of close liaison with referring paediatricians has improved the condition of infants referred to us and has led to the earlier detection of cases of coarctation of the aorta.

We thank our colleagues at the Brompton Hospital, particularly Dr M C Joseph and Mr C Lincoln, under whose care some of these children had been admitted.

\section{References}

1 Dickinson DF, Arnold R, Wilkinson JL. Congenital heart disease among 160,480 liveborn children in Liverpool 1960 to 1969 . Implications for surgical treatment. Br Heart f 1981; 46: 55-62.

2 Bound JP, Logan WFW'E. Incidence of congenital heart disease in Blackpool 1957-1971. Br Heart $\mathcal{F}$ 1977; 39: 445-50.

3 Calgren LE. The incidence of congenital heart disease in children born in Gothenburg 1941-1950. Br Heart $\mathcal{F}$ 1959; 21: 40-50.

4 Feldt RH, Avasthey P, Yoshimasu F, Kurland LT, Titus JL. Incidence of congenital heart disease in children born to residents of Olmsted County, Minnesota, 1950-1969. Mayo Clin Proc 1971; 46: 794-9.

5 Mitchell SC, Korones SB, Berendes HW. Congenital heart disease in 56,109 births. Incidence and natural history. Circulation 1971; 43: 323-32.

6 Hoffman JIE, Christianson R. Congenital heart disease in a cohort of 19,502 births with long term follow-up. Am f Cardiol 1978; 42: 641-7.

7 Fyler DC, Buckley LP, Hellenbrand WE, Cohn HE. Report of the New England Regional Infant Cardiac Program. Pediatrics 1980; 65: 375-461.

8 Richards MR, Merritt KK, Samuels MH, Langmann AG. Congenital malformations of the cardiovascular system in a series of 6053 infants. Pediatrics 1955; 15: 12-29.

9 Macartney F. A better deal for newborns with congenital heart disease. Arch Dis Child 1979; 54: 268-70.

10 Mitchell SC. The ductus arteriosus in the neonatal period. $\mathcal{F}$ Pediatr 1957; 51: 12-17.

11 Tynan MJ, Becker AE, Macartney FJ, Quero-Jiménez M, Shinebourne EA, Anderson RH. Nomenclature and classification of congenital heart disease. Br Heart $\mathcal{F}$ 1979; 41: 544-53.

12 World Health Organisation. World health statistics annual 1979. Geneva: WHO.

13 Shinebourne EA, Tam ASY, Elseed AM, et al. Coarctation of the aorta in infancy and childhood. Br Heart $\mathcal{F}$ 1976; 38: 375-80.

14 Bull C, Deanfield J, De Leval M, Stark J, Taylor JFN, Macartney FJ. Correction of isolated secundum atrial septal defect in infancy. Arch Dis Child 1981; 56: 784-6. 